\title{
Agroindústria familiar e políticas públicas no extremo sul do Brasil
}

\author{
Flávio Sacco dos Anjos ${ }^{1}$ \\ Nádia Velleda Caldas ${ }^{2}$ \\ Cínta de Oliveira ${ }^{3}$
}

\begin{abstract}
RESUMO
O objetivo do presente trabalho é o de abordar o impacto das políticas públicas de incentivo à produção artesanal no extremo sul do Brasil. Trata-se de estudo baseado em entrevistas realizadas com agricultores familiares de municípios da região de Pelotas, Estado do Rio Grande do Sul. O estudo mostrou que as políticas públicas são bastante fragmentadas e desarticuladas entre si. Esse e outros aspectos são decisivos para manter o estado de clandestinidade em que se encontra imersa a maior parte das agroindústrias nesta parte do Brasil.
\end{abstract}

Palavras-Chave: Políticas Públicas, Agroindustrialização Familiar, Sabor Gaúcho

\section{Family agro-industry and public policies in the extreme of the southern of Brazil}

\begin{abstract}
The aim of the work is to approach the impact of the public policies of incentive to the food small enterprises in the south of Brazil. It consists of a research based on interviews realized with family farmers of municipalities of the region of Pelotas, State of Rio Grande do Sul. The study verified that the public policies are very fragmented. These aspects are decisive to support the condition of stealthiness in which one finds immersed most of the family agroindustries in this part of Brazil.
\end{abstract}

Keywords: Public Policies; Family Agro-industry; Gaucho Flavor.

\section{1- INTRODUÇÃO}

Há exatamente dez anos foi fundada, no interior do Rio Grande do Sul, a "Associação dos Amigos dos Moinhos do Vale do Taquari”, uma iniciativa apoiada pela lei de incentivo à cultura, cujo objetivo central era a restauração de antigos moinhos de madeira existentes em quatro pequenos municípios (Ilópolis, Anta Gorda, Arvorezinha e Putinga) dessa parte da geografia gaúcha e que, melancolicamente, se deterioravam pela ação do tempo, do olvido e do abandono.

\footnotetext{
${ }^{1}$ Doutor, professor do Programa de Pós-Graduação em Sistemas de Produção Agrícola Familiar da Universidade Federal de Pelotas. Endereço: Caixa Postal no 354, Departamento de Ciências Sociais Agrárias, Faculdade de Agronomia, Campus universitário s/n, Pelotas, RS, CEP: 96010-970. Email: saccodosanjos@ gmail.com

2 Doutora, professora do Programa de Pós-Graduação em Sistemas de Produção Agrícola Familiar da Universidade Federal de Pelotas.

${ }^{3}$ Doutoranda em Qualidade Ambiental pela FEEVALE.
} 
A partir de então foi criado um Museu do Pão e uma rota turística (Caminho dos Moinhos) com o duplo propósito de resgatar a importância destas edificações para a dinâmica da vida econômica e social da região, mas também do legado deixado pelos imigrantes italianos, que com sua tenacidade e espírito empreendedor, sentaram as bases para que surgissem as primeiras experiências de transformação de produtos agroalimentares.

Paralelamente à recuperação de uma das edificações mais emblemáticas - o Moinho Colognese - foi produzido um vídeo (O Milagre do Pão) que conta com diversos depoimentos (agricultores, historiadores, sociólogos, etc.) que aludem à saga dos italianos desde sua chegada à região, no último quarto do século XIX. Uma das mais interessantes falas reunidas nesse filme documentário é, sem dúvida, a do filósofo e economista Eduardo Gianetti. No seu entendimento, a marca insofismável dos italianos e dos imigrantes em geral (alemães, poloneses, etc.) no sul do país foi consolidar uma cultura moral centrada naquilo que se convencionou chamar de "ética do trabalho", a qual se expressa através de um compromisso pela realização através do trabalho, algo que diferencia esta região em relação a outros lugares do Brasil.

Segundo suas próprias palavras, no Sul do Brasil "as pessoas têm muito orgulho do que fazem, têm um sentido de excelência profissional nas suas atividades, nos seus ofícios, que é muito característico da cultura europeia" (GIANETTI, 2008). Gianetti finaliza sua fala mostrando que em outras partes do país reinou uma outra ética, diametralmente oposta ao código moral que norteou a atuação dos imigrantes europeus, a qual pode ser resumida, ainda segundo Gianetti, num dos mais célebres e desconcertantes versos de Noel Rosa no conhecido samba "O orvalho vem caindo" onde magistralmente resume: "A minha terra dá banana e aipim. Meu trabalho é achar que descasque por mim”.

A alusão aos versos de Noel Rosa serve como instrumento para delimitar as diferenças em relação a outras latitudes do país onde os grandes ciclos econômicos (cana-de-açúcar, café, cacau, borracha) se basearam em cima de uma cultura de inspiração ibérica regida por uma racionalidade marcada pela exploração extrativista dos recursos naturais e pelo regime escravocrata. Viver do trabalho de outrem, seguindo esta lógica, não representa nenhum contrassenso, antes pelo contrário, assim como viver da mendicidade, pensando naqueles situados no extremo inferior da pirâmide social.

A realidade do Vale do Taquari reproduz uma realidade que é absolutamente recorrente em diversos lugares dos estados meridionais do Brasil. A aproximação que aqui realizamos serve não apenas para situar o objeto deste trabalho, mas também para estabelecer 
uma moldura conceitual mais ampla onde se inserem os processos que serão analisados nas seções subsequentes. Além dessa introdução, o artigo inclui quatro outras seções. A primeira delas visa estabelecer um marco geral sobre a formação social e histórica do Rio Grande do Sul, enquanto a segunda analisa a trajetória de consolidação da agricultura familiar enquanto categoria social e acadêmica. A terceira seção descreve a metodologia da pesquisa, enquanto a quarta expõe o marco das políticas públicas e dos programas de agroindustrialização no país e no Rio Grande do Sul. A quinta e última seção apresenta e discute os resultados da pesquisa.

\section{A FORMAÇÃO HISTÓRICA E SOCIAL DO RIO GRANDE DO SUL E DO EXTREMO SUL GAÚCHO.}

A formação social do Rio Grande do Sul, Estado situado no extremo meridional do Brasil, não pode ser compreendida sem que se faça uma alusão ao processo de colonização levado a cabo pelo governo imperial durante a primeira e a segunda metade do século XIX. Para os objetivos do presente artigo importa destacar que essa unidade federativa brasileira abriga um dos mais importantes setores da agricultura familiar desse país, não somente por sua importância numérica, mas, sobretudo pelo peso econômico e político que assume como protagonista no âmbito do abastecimento interno do país, assim como na exportação de produtos agroalimentares para diversos países do mundo.

Frente a esse fato, os analistas costumam convergir no entendimento de que o modelo de desenvolvimento que se seguiu no Rio Grande do Sul encontra-se intimamente associado ao florescimento da chamada "agricultura colonial" levada a cabo por imigrantes europeus não-ibéricos, especialmente durante a segunda metade do século XIX e a primeira metade do século XX, e do processo de acumulação de capital daí resultante, fenômeno no qual teve grande importância o conhecimento técnico dos imigrantes, procedentes, em sua grande maioria, de Alemanha, Itália e Polônia (SACCO DOS ANJOS; CALDAS, 2007, p.162).

O saber-fazer dos colonos, as condições extremas de isolamento e a existência de um mercado consumidor em expansão contribuíram para fomentar o surgimento das primeiras agroindústrias no espaço rural, cuja força de trabalho empregada era quase que exclusivamente oriunda das próprias famílias. As primeiras tafonas de farinha, alambiques, fábricas de conservas, cantinas de vinho, fábricas de embutidos e de banha suína, figuram em destaque nesse quadro que se busca delinear. Esse sistema atinge seu apogeu ao final da década de 1950. 
Todavia, essa realidade vai se modificar de forma substancial no período subsequente, como a seguir veremos, a tal ponto que o Estado brasileiro, num afã de renovar seus instrumentos de intervenção no espaço rural, decide pôr em marcha, recentemente, algumas medidas que visam restituir a importância destas práticas de agregação de valor aos produtos em virtude de fatores e circunstâncias que aprofundaremos ao longo deste trabalho.

Este estudo aborda alguns dos resultados obtidos através de uma pesquisa de caráter qualitativo que elegeu como foco de análise experiências concretas de implantação de agroindústrias artesanais em unidades familiares de produção numa região conhecida como "extremo sul gaúcho"4. Como a seguir veremos, alguns destes empreendimentos surgiram sob o impulso de políticas públicas destinadas a fomentar a agregação de valor aos produtos agrícolas e retirar da clandestinidade as pequenas fábricas rurais.

No que tange às agroindústrias, nosso trabalho recai na análise sobre a operação e condições de funcionamento desses empreendimentos, num contexto que invariavelmente lhes é desfavorável do ponto de vista da legislação fiscal e sanitária, bem como do acesso a políticas públicas no âmbito do financiamento dos processos produtivos e da comercialização de seus produtos.

Neste sentido, parte-se da premissa de que a participação e intervenção do Estado na economia não estão mais estritamente vinculadas à regulação de mercados, ou mesmo ao investimento orientado ao fomento e desenvolvimento industrial. O fato é que os últimos vinte anos coincidem com mudanças substanciais nos instrumentos e políticas, muitos dos quais dirigidos a reverter os problemas sociais e econômicos reinantes no meio rural brasileiro e gaúcho em particular.

São muitas as situações que requerem a intervenção do Estado na agricultura, como no caso de intempéries climáticas, aperfeiçoamento de condições de trabalho para agricultores, desenvolvimento tecnológico, políticas de fomento à produção, equalização de preços, bem como na implementação de medidas que possam, entre outras coisas, minimizar as disparidades existentes entre o meio urbano e rural, propiciando garantia de renda para o agricultor e contribuindo no sentido de proteger a agricultura doméstica. (LEITE, 2000)

Quando enfocamos os programas dirigidos ao desenvolvimento rural ou territorial, podemos observar alguns instrumentos de intervenção orientados a beneficiar agricultores mais empobrecidos e com dificuldades de integração ao mercado, bem como os que não

\footnotetext{
${ }^{4}$ O Extremo Sul gaúcho é assim chamado por ser a porção mais meridional do Estado do Rio Grande do Sul, na área fronteiriça à República Oriental do Uruguai, cujo município mais importante é Pelotas.
} 
tenham assegurada uma fonte de renda compatível com o atendimento de suas necessidades de consumo.

Entendemos que estas políticas, sem dúvida, devem ser diferenciadas segundo o público-alvo a que correspondem. Nesse sentido, coincidimos com Wanderley (1999:38), quando ela afirma que o setor familiar da agricultura brasileira foi sempre um setor impedido de desenvolver suas potencialidades, se comparado ao de outros países.

No plano macroeconômico, como é sabido, o Estado brasileiro, a partir da década de 1960, implementou um amplo programa de modernização do campo, fundamentalmente orientado para o aumento da produtividade, fato que resultou em um setor agrícola cada vez mais dependente e subordinado ao capital industrial. Além disso, os créditos subsidiados estiveram sempre direcionados às grandes explorações e aos produtos considerados estratégicos (destinados à exportação e/ou à substituição de importações) face às ambições do Estado autoritário.

Com efeito, algumas regiões do Brasil conseguiram adaptar-se às transformações e lograram algum êxito no sentido de aperfeiçoar suas infraestruturas produtivas, sobretudo as que se orientam ao mercado exportador na geração de commodities. Mas esta realidade não pode ser estendida a outros pontos da geografia nacional, como é particularmente o caso da porção meridional do Rio Grande do Sul, onde se insere o contexto do presente estudo. O resultado é que nos deparamos com um cenário de polarização que opõe zonas altamente dinâmicas e integradas aos grandes circuitos mercantis, enquanto outras padecem dentro de um ambiente de estancamento e crise de expectativas.

Invariavelmente são regiões que num determinado momento experimentaram ciclos de crescimento econômico, mas depois tornaram-se empobrecidas e frágeis do ponto de vista da vitalidade de seus sistemas de produção e da obsolescência tecnológica, como é precisamente o caso da microrregião de Pelotas, se temos em mente o caso das indústrias de alimentação, particularmente o gênero das conservas vegetais (pêssego, aspargo, abacaxi, morango, etc.).

É mister afirmar que durante as décadas de 1940 e 1950 foram levadas a cabo políticas voltadas ao desenvolvimento agroindustrial por meio da concessão de créditos subsidiados e de incentivos fiscais a determinados grupos econômicos. Tratava-se, em verdade, de uma estratégia deliberada do governo federal no sentido de impor um novo padrão de desenvolvimento centrado no incentivo ao grande capital comercial e agroindustrial.

Com o amplo apoio oferecido às grandes lavouras e aos produtos de exportação e/ou à substituição de importações, houve a extinção de diversas fábricas e agroindústrias artesanais 
baseadas na produção de pequena escala e de caráter familiar, tal como ficou evidenciado em municípios do Extremo Sul gaúcho.

No período subsequente, particularmente a partir das décadas de 1980 e 1990, percebeu-se, como resultado deste processo, a marginalização dos pequenos produtores diante da drástica redução de alternativas econômico-produtivas. Esse quadro se identifica plenamente com o caso da microrregião de Pelotas. Trata-se de uma parte da geografia gaúcha que historicamente demonstrou uma vocação para a produção agroindustrial, inicialmente realizada no interior de estabelecimentos familiares.

Sobre esse aspecto, vale dizer que:

O desenvolvimento local, baseado na agricultura familiar, depende fundamentalmente da intervenção estatal, regulando as assimetrias do mercado através de políticas públicas. Se deixada à própria sorte frente às forças de mercado, a agricultura familiar se transforma em alvo fácil de monopólios e intermediários que se apropriam do valor agregado da produção." (BROSE, 1999, p.58)

Ainda assim, parece claro supor que a importância da produção agrícola familiar esteve sempre subestimada. Muitos produtores resistem à sua própria aparição, desafiando as teses que vaticinavam o fim dessa forma social de produção no curso da história. Há, portanto, agricultores que, com grandes dificuldades, conseguiram moldar-se às exigências da modernidade, não obstante ser este um processo marcado por fortes descontinuidades.

Durante muito tempo a produção familiar aparecia inserida dentro de um discurso hegemônico que lhe vinculava à tradição e ao arcaísmo. Posteriormente tem-se o advento das novas tecnologias que avançam ao calor do processo de penetração do capitalismo no campo. No curso dessa trajetória, o savoir-faire dos camponeses representava a quintessência de um mundo em decadência que devia ceder ante os apelos da modernidade.

Porém, se existe hoje uma categoria disposta a implementar estratégias de adaptação e resistência, esta é precisamente a agricultura familiar. Esse tipo de exploração agrária é regido por uma lógica de funcionamento própria, o que nos leva a pensar que simplesmente não se pode analisar a agricultura familiar somente sob a ótica da produção, da racionalidade econômica ou da divisão do trabalho (CARNEIRO, 2000, p.129). Com efeito:

por conta das necessidades, das carências ou do desengajamento do Estado dos seus compromissos reguladores, os agricultores constroem dispositivos alternativos. Assiste-se, no Brasil, a uma multiplicação de iniciativas de manejo de recursos comuns ou de produção de bens públicos por grupos de agricultores (SABOURIN, 2006, p. 228). 
A agricultura familiar começa a ser mais valorizada no momento específico em que se dá o reconhecimento, por parte do Estado e de certos setores da sociedade brasileira, do papel desempenhado por este amplo e diversificado setor. Há, decerto, um debate no qual são confrontados os resultados alcançados pela agricultura patronal com os da agricultura familiar, particularmente do ponto de vista da ocupação da população rural, da vitalidade do tecido produtivo nas pequenas localidades e do abastecimento alimentar da população. Todavia, nesse processo, a ênfase é colocada sobre os agricultores familiares com potencial para vincular-se ao mercado e com capacidade de incorporar as tecnologias modernas, fato que acarreta a exclusão dos demais, considerados incapazes de atender às demandas do mercado. (CARNEIRO, 2000, p. 133)

Até aqui nossa atenção esteve posta na apresentação do marco geral das grandes questões que afetam ao escopo da pesquisa. Cabe agora trazer alguns aspectos que evidenciam a importância das políticas públicas para a agricultura familiar dos municípios da microrregião de Pelotas que, como dissemos anteriormente, corresponde ao universo empírico da pesquisa. Mas torna-se crucial situar essa forma social de produção dentro do contexto histórico-social em que ela se insere. É essa a tarefa que se busca desenvolver na próxima secção do artigo.

\section{A AGRICULTURA FAMILIAR NO SUL DO BRASIL}

Como é sabido, o Extremo Sul gaúcho é marcado por um grande número de estabelecimentos agrícolas de caráter familiar, não obstante a presença de grandes propriedades que resultaram do desmembramento das antigas estâncias surgidas ainda no século XVIII (KLIEMANN, 1986).

A distribuição das terras do extremo sul foi feita sob a forma de sesmarias, especificamente destinadas para aqueles que, de alguma forma, haviam servido à Coroa Portuguesa, ou que dispusessem de recursos para investir na produção (GRANDO, 1990). Neste contexto, "A concessão de datas e sesmarias incentiva o crescimento de grandes propriedades, na sua maioria latifúndios de base pecuarista”. (KLIEMANN, 1986, p. 17)

Kliemann (1986, p. 18) alude o fato de que a pequena propriedade era praticamente inexistente durante a primeira fase de ocupação do território gaúcho. A origem destas explorações se atribui ao processo de colonização empreendido na segunda metade do século XIX. A colonização, mediante assentamento de imigrantes europeus, serviu, entre outros 
objetivos, para operar a substituição da mão-de-obra escrava nas grandes propriedades rurais. (SACCO DOS ANJOS; GODOY; CALDAS, 2005, p.75) Além disso,

Apesar da política de colonização assegurar a manutenção do latifúndio, esta acabou originando, no Rio Grande do Sul, um importante setor camponês, com acesso limitado à terra e meios precários de produção, baseado na divisão familiar do trabalho e numa atividade econômica fortemente diversificada. (SACCO DOS ANJOS; GODOY; CALDAS, 2005, p.75)

Neste contexto,

A economia camponesa foi instaurada, no Sul do Brasil, em condições precárias no que se refere tanto ao meio rural quanto aos recursos. Contudo, onde havia mercado consumidor, viabilidades de comunicação e terras férteis, as colônias progrediam, formando uma paisagem nova e bastante característica (GRANDO, 1990, p .64).

Por outra parte, nos anos de 1890 a 1910, o estado do Rio Grande do Sul conheceu o surgimento de novas colônias onde começam a consolidar-se pequenas comunidades, bastante dispersas e com grandes dificuldades de comunicação. O esforço por viabilizar sua sobrevivência resultou no aparecimento de pequenas fábricas artesanais nestas comunidades que desenvolviam não só suprimentos, mas inclusive as próprias ferramentas e utensílios. Eram pequenas economias em cada região do Estado e que somente em 1920 começaram a se integrar e atingir mercados mais distantes, conforme reitera Tambará (1985, p. 33) em seu estudo. É sobretudo a partir da segunda metade do século XIX que se inicia o processo de colonização privada em Pelotas, com o assentamento de imigrantes, especialmente de origem alemã, italiana e francesa. Até meados de 1900 foram criados 61 núcleos coloniais.

O fato é que:

em meados de 1870 , percebe-se que as colônias instaladas na região passam a ter uma importância significativa na economia local, provocando alterações na paisagem e na rotina da cidade, devido ao intenso fluxo de produtos coloniais ofertados, o que obrigou o poder público local a tomar medidas administrativas para organizar o comércio local, [...]. (SACCO DOS ANJOS; GODOY; CALDAS, 2005, p.84).

Também cresceu muito o número de "moinhos coloniais" na região devido ao grande incentivo governamental, à época, para o plantio de trigo, fato que levou a que muitos agricultores familiares ampliassem suas áreas de produção, juntamente com o desenvolvimento de outras atividades produtivas, como é o caso da produção de derivados cárnicos, banha e outros artigos, além de conservas e compotas vegetais.

Porém, a partir da década de 1950 é promulgada a Lei $\mathrm{n}^{\circ} 1.283$ referente à inspeção industrial e sanitária de produtos de origem animal. Ela determinava que todos os 
estabelecimentos que trabalhassem com produtos de origem animal deveriam ser rigorosamente inspecionados.

Neste contexto, a crescente exigência de equipamentos necessários para o abate de animais e manuseio dos produtos agrícolas torna-se incompatível com a realidade das colônias, fazendo com que muitos agricultores familiares, que produziam nas cozinhas de suas casas, ou em área específica fora do ambiente doméstico, acabassem encerrando suas atividades. A lei para a sanidade dos alimentos era condizente com a dinâmica operacional das grandes indústrias, deixando na clandestinidade as pequenas fábricas artesanais, as quais eram consideradas, no plano do discurso oficial, como despossuídas de condições mínimas para adequarem-se à nova realidade, tal como alude Prezotto $(1999$, p.44) em seu estudo.

Some-se a isso o fato de que no ano de 1967 ocorreu a cartada final para a autonomia do agricultor familiar, pois, de acordo com Abramovay (198, p.161), com o decreto-lei 210/67 os moinhos coloniais, que até então se dedicavam à produção de trigo, foram extremamente atingidos devido à intervenção do Estado no âmbito da comercialização e industrialização deste cereal. Estabeleceu-se, à época, o monopólio estatal do trigo, via Banco do Brasil, cabendo exclusivamente ao Governo Federal a compra desse produto. A partir de então, aos moinhos eram concedidas cotas de trigo para a moagem, segundo um padrão de qualidade da farinha a ser produzida, estabelecendo-se preços para o produto in natura e para a farinha, conforme convinham aos interesses do Estado.

Crescem as exigências impostas pelas indústrias no sentido da padronização e regularidade na oferta de produtos. Paralelamente os produtores são forçados a incorporar inovações tecnológicas exigidas para adequarem-se a esses imperativos e ao crescente nível de exigência das fábricas do setor agroalimentar.

Ocorreram mudanças expressivas na dinâmica do trabalho agrícola, em que pese o fato das indústrias de transformação passarem a ter um controle, cada vez mais rígido, sobre o processo de trabalho e sobre os produtos oferecidos por estes agricultores (MATTEI, 1998). Estes passam também a procurar outros tipos de trabalho e a exercer outras ocupações como forma de atender suas necessidades de consumo. No estudo realizado sobre a "colônia francesa” em Pelotas, Grando (1990), esclarece.

A particularidade dos camponeses de Pelotas é a de serem especializados de forma incompleta, na medida em que produzem maciçamente legumes e frutas para $\mathrm{o}$ mercado industrial, mas mantém ativo o velho sistema da policultura associada à pecuária de pequeno porte, base de sua sobrevivência." (GRANDO, 1990, p.123) 
A agricultura familiar desta região ainda sente o reflexo das políticas dissociadas da preocupação com o desenvolvimento social e econômico no âmbito das comunidades rurais que, paulatinamente, assistem a uma sensível redução das alternativas de ingresso econômico e de ocupação das famílias.

Hoje, procurando resgatar exatamente as potencialidades destes agricultores familiares e o fortalecimento desse setor da agropecuária nacional, os governos federal e estadual propõem políticas públicas de fomento a programas de agroindustrialização e de certificação de produtos, como forma de criar novas oportunidades no meio rural e resgatar um traço tão característico dessa forma social de produção, que apesar de suas limitações e crescentes dificuldades, tem contribuído para o desenvolvimento rural do Sul do Rio Grande do Sul.

Partimos da premissa de que as agroindústrias familiares enaltecem um atributo crucial inerente à dinâmica da agricultura familiar, propiciando maior grau de autonomia às famílias e contribuindo para a diversificação da economia no meio rural. Esse aspecto é fundamental para os objetivos do presente trabalho e será aprofundado posteriormente. Antes, porém, cabe explicitar a metodologia que sustentou a obtenção dos dados desta pesquisa.

\section{METODOLOGIA DA PESQUISA}

A realização desta investigação está diretamente vinculada à dissertação de mestrado defendida em 2009 junto ao Programa de Pós-Graduação em Ciências Sociais da Universidade Federal de Pelotas, RS. Nesse sentido, surge como resultado de uma aproximação que realizamos durante três anos de intenso contato com a realidade rural de municípios que integram a Microrregião de Pelotas.

A primeira etapa da pesquisa que ensejou a elaboração desse artigo, correspondeu a uma revisão de literatura, levantamento de dados e informações referentes à agricultura familiar, seguida de uma aproximação in situ, orientada à busca de informações sobre as etapas e condições em que opera o processo de agroindustrialização em alguns estabelecimentos familiares da região de Pelotas.

Há, por certo, centenas de estabelecimentos rurais que realizam algum tipo de transformação e beneficiamento de produtos de origem animal e vegetal. Nesse sentido, a parte inicial da pesquisa envolveu a realização de visitas técnicas a 28 explorações agrícolas familiares. Nessa etapa, tratava-se de buscar subsídios à tarefa de estabelecer um recorte de realidade, mas, sobretudo de obter elementos que nos permitissem definir quais os 
estabelecimentos poderiam ser escolhidos como representativos da realidade que nos propomos desvendar.

Não se trata, portanto, de uma pesquisa resultante de uma amostra aleatória, dado que nossa atenção esteve posta no estudo sobre agroindústrias de base familiar que estivessem em pleno funcionamento e que houvessem, ou não, sido apoiadas por programas públicos de financiamento em sua construção, ampliação ou reforma realizada nos últimos cinco anos. Nosso objetivo era justamente desvelar as razões adotadas pelos agricultores para desenvolver esse tipo de iniciativa, o papel correspondente às políticas públicas e as expectativas das famílias em relação ao futuro dos próprios empreendimentos.

Esses objetivos e o entendimento geral das questões suscitaram alguns desafios no desenho da pesquisa. Há uma grande heterogeneidade entre os estabelecimentos que realizam agregação de valor aos seus produtos e muitos deles funcionam de forma intermitente e/ou precariamente, ao longo do ano agrícola. A escolha dos entrevistados baseou-se nas orientações prestadas pelos agentes da extensão rural oficial, técnicos de organizações não governamentais que atuam na região e por informações disponibilizadas por membros de sindicatos de trabalhadores rurais. Esse contato envolveu a realização de quatro entrevistas com atores-chave ligados às organizações que atuam no espaço rural acima aludido.

Trata-se, portanto, de um estudo com um foco bastante delimitado, diferentemente de uma abordagem apoiada na aleatoriedade e numa amostra expandida, a qual, logicamente, presta-se a outros esquemas de investigação científica, a exemplo do tipo survey, onde o objetivo essencial é produzir descrições quantitativas de uma população determinada.

Ao final realizamos nove entrevistas em profundidade, sendo uma delas com um representante do Ministério do Desenvolvimento Agrário e outra com o Supervisor de crédito da Emater Regional de Pelotas. As sete (07) entrevistas restantes foram realizadas com os responsáveis de agroindústrias localizadas nos municípios de Pelotas, São Lourenço do Sul, Cerrito, Herval e Canguçu, sendo que cinco (05) delas encontravam-se legalizadas e as demais em processo de legalização. Todas elas encontravam-se em pleno funcionamento. Os dados que a seguir serão apresentados e discutidos consistem numa pequena parcela de toda informação analisada, correspondendo a aproximadamente 36 horas de entrevistas gravadas mediante uso de equipamento eletrônico, as quais foram transcritas, sistematizadas e analisadas, segundo o método da análise de discurso. 


\section{POLÍTICAS PÚBLICAS E PROGRAMAS DE AGROINDUSTRIALIZAÇÃO}

Atualmente há alguns instrumentos e políticas públicas de fomento à agroindustrialização no Estado do Rio Grande do Sul, os quais emanam tanto da esfera federal quanto estadual e, inclusive, da esfera municipal. No trabalho de campo destacam-se situações em que houve o acesso ao Programa Nacional de Fortalecimento da Agricultura Familiar (doravante Pronaf), na modalidade Agroindústria, e o Programa de Agroindustrialização Familiar, mais conhecido como "Sabor Gaúcho", levado a cabo exclusivamente nessa unidade federativa brasileira com recursos do governo estadual.

No que tange ao primeiro deles, trata-se de um instrumento específico, de alcance federal, para financiar agroindústrias médias e pequenas. Este tipo de crédito é dado a agricultores que tenham sua propriedade rural regularizada (título de propriedade ou concessão de domínio) e o potencial necessário para inserirem-se nos mercados com base no associativismo e na formação de redes de cooperação para a compra e venda de produtos. (PREZOTTO, 1999). Mas cabe advertir que dificilmente o Pronaf Agroindústria é liberado a agricultores isoladamente, pois que, em geral, é dada preferência a agricultores associados em grupos, conforme indica Prezotto (1999, p.116).

À época da pesquisa os agricultores que acessavam o Pronaf deviam ter pelo menos $80 \%$ de sua renda oriunda das atividades agropecuárias, explorando até quatro módulos fiscais ${ }^{5}$, ou no máximo seis, quando se tratasse de um "pecuarista familiar". Também constam como público-alvo do Pronaf os agricultores que exerçam atividades como arrendatários, parceiros ou meeiros. Todavia, nos termos do programa, do agricultor familiar se admite a contratação de até dois empregados permanentes. (SCHNEIDER; CAZELLA; MATTEI, 2004)

Era exigido dos produtores que residissem no imóvel rural ou nas proximidades rurais, com renda bruta deve ser de no máximo de $\mathrm{R} \$ 60.0000,00$. Com respeito ao Pronaf Agroindústria, cabe reiterar que a intenção desta linha do programa é justamente explorar as potencialidades da propriedade rural, associando a produção gerada no âmbito da pequena propriedade rural com a formação da agroindústria familiar. (SCHNEIDER; CAZELLA; MATTEI, 2004) Nesse sentido, a modalidade custeio do Pronaf Agroindústria Familiar era direcionada às demandas correntes da empresa familiar, como no caso da compra de matéria

\footnotetext{
${ }^{5}$ O Módulo Fiscal tem área definida por município e tipo de exploração (intensiva ou extensiva) e corresponde a uma área capaz de assegurar a reprodução social de um produtor e de sua família, segundo define o Estatuto da Terra e a legislação agrária federal.
} 
prima, rótulos, embalagens, entre outros insumos consumidos durante o processo de produção.

O segundo instrumento de política pública sobre o qual nos debruçamos a investigar foi o Programa de Agroindustrialização Familiar "Sabor Gaúcho”. Criado em 1999, durante a administração do governador Olívio Dutra do Partido dos Trabalhadores, buscava beneficiar a produção de agricultores familiares, assentados da Reforma Agrária e pescadores artesanais no Rio Grande do Sul. Em linhas gerais, tratava-se de fomentar novas possibilidades e estratégias que atenuassem as dificuldades econômicas das famílias rurais, diversificando as fontes de ingresso econômico e ampliando suas possibilidades no cenário local e regional para esse fragilizado setor da sociedade. Tratava-se, em suma, de evidenciar o compromisso de um governo popular em seu afã de mostrar a inversão de prioridades, elegendo os pequenos, em detrimento dos grandes empreendimentos econômicos.

Através do aludido programa pretendia-se oferecer ao agricultor familiar outras formas de sustentação material, em consonância com as potencialidades de cada região, conforme reiteram documentos oficiais (RIO GRANDE DO SUL, 2002 p. 12).

Outro ponto importante é que os produtos comercializados e vendidos via Nota do Produtor eram isentos da cobrança do Imposto de Circulação de Mercadorias e Serviços (ICMS). O agricultor vinculado ao selo "Sabor Gaúcho" contaria, além disso, com propaganda gratuita para seu produto, além de gôndolas para exposição, rótulos, marketing, cursos e capacitação para inserirem-se nos mercados e participarem de feiras e exposições agropecuárias.

Poderiam participar do programa as famílias individuais ou organizadas em grupo, e que atendessem, conforme documentos do Governo do Estado (RIO GRANDE DO SUL, 2002, p. 38), às seguintes exigências:

a) que $80 \%$ da renda familiar fosse oriundo da atividade agropecuária, pesca ou extrativismo;

b) que o estabelecimento utilizasse exclusivamente a mão-de-obra familiar nos processos de produção;

c) que a propriedade familiar tivesse até quatro módulos fiscais;

d) que o produtor e sua família residissem na propriedade rural ou em aglomerados rurais próximos

e) que a família auferisse uma renda bruta de anual de até $\mathrm{R} \$ 30$ mil. 
O programa se apresentava à sociedade gaúcha como comprometido com o esforço de amenizar as dificuldades inerentes às pequenas e médias agroindústrias, como no caso da incapacidade de obter ganhos à escala, deficiências de gerenciamento, falta de padronização e de qualidade na produção, baixo nível de organização dos agricultores, infraestrutura pública insuficiente, dificuldades quanto às legislações sanitária, fiscal e tributária, somada à falta de estudos de viabilidade econômica financeira e técnica para essa classe de empreendimento.

Todo o cuidado com a impressão dos rótulos, embalagens, códigos de barras, o próprio selo e a tabela nutricional corriam a cargo das diretrizes de um Programa que constava como uma das grandes bandeiras do Partido dos Trabalhadores em seu esforço por inverter as prioridades convencionalmente assumidas pelos governos anteriores.

Através do "Sabor Gaúcho" o produtor continuaria a utilizar a Nota do Produtor, desde que fosse microprodutor e estivesse efetivamente cadastrado no Programa de Agroindústria Familiar, produzindo 100\% da matéria-prima consumida em sua agroindústria, além de estar enquadrado dentro das exigências da vigilância sanitária e das normas apregoadas pelo Sabor Gaúcho. Dito programa mantinha um selo de qualidade que pertencia ao Governo Estadual, o que trazia clara diferenciação à marca. (RIO GRANDE DO SUL, 2002:39)

Os programas de agroindustrialização apresentados visavam atingir um perfil de agricultores familiares com vocação para o empreendimento, os quais eram escolhidos de acordo com a capacidade e o interesse de aprimoramento e qualificação profissional. As restrições orçamentárias e os riscos implicados nesses processos justificavam uma criteriosa escolha dos beneficiários destes programas, levando em conta esses e outros aspectos que, ao fim e ao cabo, são decisivos para determinar o êxito ou o fracasso destes pequenos empreendimentos.

\section{AS POLÍticAS DE AGROINDUSTRIALIZAÇÃO FAMILIAR E ALGUNS DE SEUS RESULTADOS NO EXTREMO SUL GAÚCHO}

No território pesquisado, que compreendeu os municípios de Pelotas, São Lourenço do Sul, Cerrito, Canguçu e Herval, encontramos relatos importantes para afiançar o atendimento dos objetivos que nortearam a realização desta pesquisa. Com respeito à finalidade do programa, percebeu-se que os agricultores familiares que foram beneficiados por estes programas adquiram certo grau de autonomia, se comparados com a situação de 
famílias que dependem exclusivamente de uma ou duas fontes de ingresso econômico, como é o caso dos que se encontram na condição de integrados às empresas fumageiras. O trabalho de campo evidenciou a situação de apenas uma família que não vive exclusivamente da comercialização da produção originada em sua agroindústria.

Coincidimos com Prezotto (2002, p.16), no sentido de entender que a agroindústria familiar é uma das formas pelas quais é possível amenizar as disparidades sociais no campo, consistindo no exercício de uma forma de pluriatividade $^{6}$ que reflete uma estratégia específica, capaz de gerar postos de trabalho diretos e indiretos, além de assegurar uma inserção econômica mais consistente, por parte dos agricultores familiares, junto aos mercados.

Entrementes, todos os responsáveis pelos empreendimentos entrevistados queixaramse de problemas relacionados às imposições das legislações sanitária e fiscal. O fato é que atualmente o agricultor familiar que pretende montar uma agroindústria na propriedade terá duas opções: ou se transforma em um microempresário, arcando com todas as exigências tributárias e fiscais referentes à condição de empresa ou, de outro modo, monta uma cooperativa que congregue agricultores que tenham basicamente os mesmos objetivos e formas de atuação, o que não é uma tarefa simples de concretizar diante do atomismo em que se encontra imersa a maioria dos produtores. Mas se seguir esse caminho, poderá ter que renunciar à sua condição de segurado especial da Previdência Social.

Abrir mão de sua condição de agricultor e da possibilidade futura de conquistar seu direito à aposentadoria, em regime especial, tem sido apontado como um grande problema, reiterado claramente nas entrevistas que realizamos. Ainda que limitada a um salário-mínimo, é uma renda segura que nem sempre se consegue obter como produtor de alimentos e de matérias-primas, em meio a um cenário marcado pela incerteza e pela precariedade do trabalho no espaço rural.

Percebemos também que atualmente as agroindústrias familiares originadas a partir do Programa de Agroindustrialização Familiar - Sabor Gaúcho não gozam mais do respaldo que tinham por parte do Governo Estadual. Trata-se de um programa concebido durante o Governo de Olívio Dutra que, ao fim e ao cabo, não teve continuidade nos governos subsequentes (Yeda Crusius e Germano Rigotto).

Não foram criadas novas agroindústrias familiares através desse ou de outros programas públicos estaduais, assim como não ocorreram avanços no sentido de melhorar a

${ }^{6}$ Sobre o conceito de pluriatividade ver SACCO DOS ANJOS; CALDAS (2007). 
legislação sanitária e fiscal, visando aperfeiçoá-la e, sobretudo, adequá-la às condições dos empreendimentos rurais.

Neste contexto, algumas conquistas, particularmente para os agricultores vinculados ao programa, não tiveram mais continuidade. O marco legal atual, que regula esta atividade torna impeditivo avançar no processo de comercialização, dado que é aplicável essencialmente para o caso dos grandes empreendimentos. Alguns relatos esclarecem tais aspectos e refletem uma visão, que em alguns casos, mostrava-se como bastante pessimista com relação ao futuro de iniciativas desta natureza: "Eles criaram a ideia, nos venderam a ideia e sumiram. Para ser sincero, o Sabor Gaúcho não existe mais." (informação verbal ${ }^{7}$.)

Outro entrevistado é ainda mais enfático:

Hoje a agroindustrialização, a agroecologia não é mais prioridade, pelo contrário, a política é de trabalhar com agronegócio, então dificulta muito a vida deles, um exemplo claro é a questão da legislação, que bom... uma das grandes dificuldades é a questão tributária, de como vai vender, de como vai comercializar esse produto. $\mathrm{Na}$ época do Sabor Gaúcho foi feita uma legislação específica onde eles podiam vender com a nota do produto, que é um meio precário, que tem suas limitações. Mas é interessante na medida em que as agroindústrias podiam se legalizar sem ter um CNPJ [Cadastro Nacional de Pessoa Jurídica]. (informação verbal ${ }^{8}$ )

Quanto ao Pronaf Agroindústria, este é ainda mais restritivo do que o Sabor Gaúcho, especialmente no que se refere à obtenção de crédito. Em nossas entrevistas apenas um produtor havia conseguido acessar esse tipo de financiamento, o qual legalizou sua agroindústria para ampliar o acesso aos mercados e que, à época da entrevista, estava exclusivamente restrito às feiras livres. Porém, de acordo com nosso entrevistado, a falta de divulgação e a burocracia para a retirada de crédito inviabiliza este esforço, dificultando a montagem de novas agroindústrias e a ampliação das já existentes: "Gestão, isso sim, estrutura, escala, muita burocracia. O agricultor, assim, detesta burocracia nós já detestamos, imagina o agricultor. Não entende, não é o universo dele." (informação verbal ${ }^{9}$ ). Já segundo outro de nossos entrevistados:

Os agentes financiadores não aceitam em hipótese nenhuma. Tu financiar um prédio para fazer tua indústria. Ele só aceita, ele só te libera o recurso se tu provar que tu tens garantias, no caso se a terra é de terceiros e tu tem contrato de arrendamento, por

\footnotetext{
${ }^{7}$ Informação fornecida por A. M. (agricultor), em entrevista concedida no município de Cerrito, Jul/2007.

${ }^{8}$ Informação fornecida por J.S.S. (técnico, agrônomo), em entrevista concedida no município de Pelotas, Mar/2008.

${ }^{9}$ Informação fornecida por E. S. M. (técnico, agrônomo), em entrevista concedida no município de Pelotas Mar/2008.
} 
exemplo, se ele te deu garantia que teu arrendamento é por vinte, trinta anos ou mais. (informação verbal ${ }^{10}$ )

A questão é que fomentar a criação de agroindústrias sem um amparo institucional adequado acarreta resultados incompatíveis com os próprios objetivos consagrados nesse tipo de programa. Entendemos que a indefinição sobre o público que se quer alcançar tem levado a que muitas iniciativas sejam relegadas ao fracasso, na medida em que se concebe o universo da agricultura familiar de forma homogênea, sem levar em conta toda a diversidade que encerra esse setor, ou seja, sem uma análise precisa de qual processo da agroindustrialização e tipo de agroindústria se quer lograr erigir. (GUIMARÃES; SILVEIRA, 2007, p.35)

Com efeito:

Uma unidade de produção agrícola familiar não funciona como uma empresa capitalista convencional. [...]. Tal unidade preenche também outras funções, e seus mecanismos de funcionamento dificilmente se limitam aos mecanismos econômicos. Mesmo a integração crescente aos mecanismos do mercado não pode levar a uma ruptura radical do vínculo osmótico entre a família e a unidade de produção. (BRITO, 2005, p. 82)

Alguns autores consideram que, em verdade, tenta-se simplesmente mitigar a exclusão dos agricultores mais empobrecidos com programas, muitas das vezes, ineficientes, onde o que se busca é a compatibilização de políticas de desenvolvimento rural e políticas agrícolas. (DELGADO, 2001, p. 26)

Dois de nossos entrevistados alegaram que o fato de muitas agroindústrias não haverem sido alcançadas por programas como "Sabor Gaúcho" deve-se, algumas das vezes, à própria vontade do agricultor em se manter no estado de total clandestinidade. Além disso, à época em que surgiu esse programa, a situação financeira e as condições de funcionamento de muitos desses empreendimentos não eram condizentes com a capacidade de contrair dívidas para a aquisição de equipamentos. Ainda assim, muitos deles demonstram interesse em participar de programas de capacitação e de cursos para diversificação de seus produtos e fontes de ingresso econômico. Conforme relato,

Têm várias que estão bem e estão muito bem obrigado, mas é que como o programa de Agroindústria oferecia vários benefícios para o agricultor desde a venda em bloco de produtor, aí tinha a parte de código de barra, tinha legalização, tinha financiamento, tinha treinamentos, [...] tinha umas que se apresentavam só para treinar. [...] de repente

\footnotetext{
${ }^{10}$ Informação fornecida por E. S. M. (técnico, agrônomo), em entrevista concedida no município de Pelotas Mar/2008.
} 
continuavam ilegais porque a estratégia dele era só um treinamento. (informação verbal $^{11}$ )

Com base nas entrevistas, buscou-se realizar uma aproximação à realidade em que operam essas agroindústrias. Entendemos que os processos de agroindustrialização representam uma possibilidade concreta para resgatar a autonomia das famílias diante da crescente dependência a que foram submetidas a partir da especialização produtiva, bem como para apoiar o desenvolvimento rural no sentido de ampliar as possibilidades de ocupação e renda dos indivíduos.

Mas a conclusão geral a que chegamos, com base no contato com a realidade concreta, é que nenhum programa conseguirá atingir seus objetivos sem uma ação articulada, coordenada e consistente no que afeta ao financiamento dos empreendimentos, no apoio à qualificação dos processos produtivos, no acesso aos mercados, formação profissional e a um ambiente institucional que efetivamente propicie o sucesso destes empreendimentos.

O agricultor familiar que ingressou em Programas como o Sabor Gaúcho, e que teve acesso a essa classe de apoio institucional, era igualmente incitado a ser mais ousado e competitivo no enfrentamento das conhecidas adversidades, a exemplo dos custos crescentes de produção, transporte e distribuição, frente aos quais, invariavelmente tem dificuldades de assumir de forma isolada ou individual.

Porém, após optar pela transformação de sua agroindústria familiar em uma microempresa, sente-se totalmente fragilizado ao não contar com o necessário amparo e proteção dos poderes públicos, em meio aos efeitos de um mercado fortemente competitivo e regido pela presença de oligopólios na produção, comércio e distribuição de produtos reconhecidamente indiferenciados. As grandes superfícies de comércio mostram-se invariavelmente refratárias ao ingresso de produtos locais, que aqui aludimos como portadores de singularidades, também chamados de artigos regionais, artesanais ou típicos.

$\mathrm{O}$ estudo aqui desenvolvido convergiu no entendimento de que todos estes programas serão sempre muito limitados, enquanto aos seus respectivos alcances, se persistir o atual quadro de desarticulação com outras políticas de apoio ao setor familiar da agricultura nacional. Há, por certo, um conjunto de fatores que conspiram para preservar o estado de clandestinidade em que se encontra imersa a maior parte das agroindústrias familiares do Sul gaúcho no atual contexto.

\footnotetext{
${ }^{11}$ Informação fornecida por E. S. M. (Agrônomo), em entrevista concedida no município de Pelotas Mar/2008.
} 


\section{REFERÊNCIAS}

ABRAMOVAY, R. Transformações na vida camponesa - o sudoeste paranaense. São Paulo, 1981. 179 f. Dissertação (Mestrado em Ciência Política), Programa de Pós-Graduação em Ciência Política da Faculdade de Filosofia, Letras e Ciências Humanas, Universidade de São Paulo, São Paulo. 1981.

BRITO, C. de O. A agroindústria artesanal e o Programa Fábrica do Agricultor: uma tentativa de racionalizar as atividades em uma unidade de produção agrícola familiar. Curitiba, 2005. 103 p. Dissertação (Mestrado em Sociologia). Programa de Pós-Graduação em Sociologia da Universidade Federal do Paraná. 2005.

BROSE, M. 1999. Agricultura familiar, desenvolvimento local e políticas públicas. Santa Cruz do Sul: EDUNISC, 347p.

CARNEIRO, M. J. Políticas de desenvolvimento e o novo rural. In: CAMPANHOLA, C. GRAZIANO DA SILVA, J. (Orgs.). O novo rural brasileiro: políticas públicas. 1ed. Jaguariúna, São Paulo: EMBRAPA Meio Ambiente, 2000, v. 4. p. 117-150.

DELGADO, N. G. Política econômica ajuste externo e agricultura. In: LEITE, S. P. (Org.) Políticas Públicas e Agricultura no Brasil. Porto Alegre: Ed. Da UFRGS, 2001, p. 17-54.

GIANETTI, E. Criar o paraíso. In: FERRAZ, I. G. O milagre do pão. [Filme-documentário]. Direção Isa Grinspum Ferraz. São Paulo: Centro de Pesquisa e Documentação da Fundação Nestlé, 2008. 1 DVD, 55 min. color. son.

GUIMARÃES, G.M.; SILVEIRA, P. R. C. Por Trás da Falsa Homogeneidade do Termo Agroindústria Familiar Rural: Indefinição Conceitual e Incoerências das Políticas Públicas. In: VI ENCONTRO DA SOCIEDADE BRASILEIRA DE SISTEMAS DE PRODUÇÃO, 2007, Fortaleza, Anais... Fortaleza: SBSP, 2007.

GRANDO, M.Z. Pequena agricultura em crise. Porto Alegre: FEE, 1990, 209p.

KLIEMANN, L. H. S.. RS: Terra e poder - história da questão agrária. Porto Alegre: Mercado Aberto, 1986. 176p.

LEITE, S. P. Políticas Públicas e Agricultura no Brasil. Porto Alegre: Ed. da UFRGS, 2001 $256 \mathrm{p}$.

MATTEI, L. A evolução do emprego agrícola no Brasil. São Paulo: ABET, v. 4, 1998, 109p.

PREZOTTO, L.L. A Agroindústria Rural de Pequeno Porte e o seu Ambiente Institucional Relativo à Legislação Sanitária. Florianópolis, 1999. 143 p. Dissertação (Mestrado em Agroecossistemas) Programa de Pós-Graduação em Agroecossistemas. Universidade Federal de Santa Catarina, Florianópolis, 1999.

PREZOTTO, L. L. Uma concepção de Agroindústria Rural de Pequeno Porte. Revista de Ciências Humanas, n. 31, p. 133-154. 2002. 
RIO GRANDE DO SUL. Secretaria de Agricultura e Abastecimento - SAA. Agroindústria Familiar - Gerando Trabalho e Renda no Campo e na Cidade. Porto Alegre: EMATER/RS, 2002.

SABOURIN, E. Práticas sociais, políticas públicas e valores humanos. In: SCHNEIDER, S. (Org.). A diversidade da agricultura familiar. Porto Alegre: Editora da UFRGS. 2006, p. $108-132$.

SACCO DOS ANJOS, F.; CALDAS, N. V. Pluriactividad y agricultura familiar en Brasil: el caso de Rio Grande do Sul. Revista de La Cepal, Santiago do Chile, nº. 93, p.157.173, 2007.

SACCO DOS ANJOS, F.; GODOY, W. I.; CALDAS, N. V. As feiras-livres de Pelotas sob o império da globalização: perspectivas e tendências. Pelotas: Ed. da UFPel, 2005, 195 p.

SCHNEIDER, S., S., M. K., MARQUES, P. E. M.; CAZELLA, A.A. Políticas Públicas e Participação Social no Brasil Rural. Porto Alegre: Ed. da UFRGS, 2009, 256p.

TAMBARÁ, E. RS: modernização \& crise na agricultura. 2 • ed. Porto Alegre, Mercado Aberto, 1985.95p.

WANDERLEY, M. N. B.. Raízes históricas do campesinato brasileiro. In: TEDESCO, J. C. (Org.). Agricultura familiar: realidades e perspectivas. Passo Fundo: EDIUPF, 1999, p. 23-56. 